\title{
The mediation role of motivation between leadership and public sector performance
}

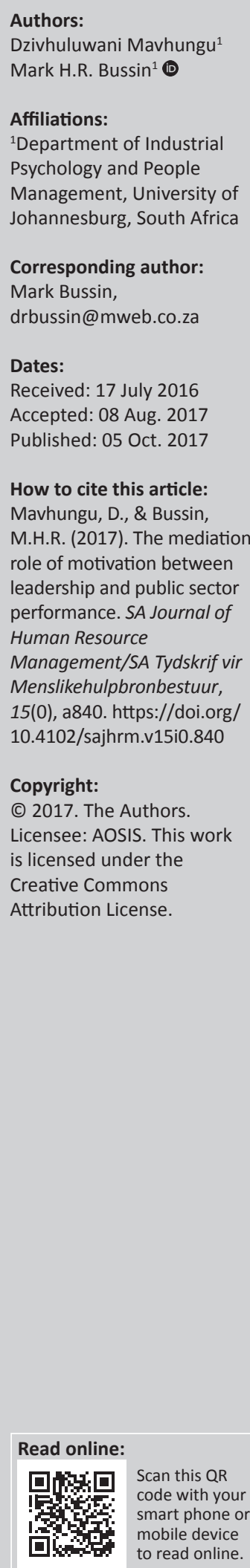

Orientation: As a result of poor performance in 2013, five departments in the Limpopo province were placed under administration in terms of Section 100 (1) (b) of the Constitution of the Republic of South Africa.

Research purpose: The main purpose of this study was to investigate the importance of the individual level of performance when diagnosing performance issues in the public sector by focusing on the mediatory role of motivation in the relationship between leadership and public sector performance.

Motivation for the study: The diagnosis conducted focused more on the analysis of administrative and operational systems. The solutions were based on normalising financial statements and systems to improve performance.

Research design, approach and method: The study took a positivist approach as the philosophy of the study. Using quantitative methods, a cross-sectional survey was used to collect data from 65 employees working in one of the departments that were affected by the intervention.

Main findings: The study confirmed the existence of a relationship between leadership and performance in the public sector. It was also found that Public Sector Motivation plays a mediatory role between Perceived Leadership Styles and Individual Job Performance.

Practical/managerial implications: The findings imply that it is important that the Limpopo Provincial Government makes an effort to employ and retain employees who are readily showing high levels of Public Sector Motivation.

Contribution or value additions: The study focused on an overlooked area in the study of performance in the public sector. The study was able to produce a tool that should be able to provide information to assist managers to make better performance improvement strategy decisions.

\section{Introduction}

\section{Key focus of the study}

There has been notable increase in the academic interest in Public Service Motivation in the last 12 years (Bozeman \& Su, 2014; Van der Wal, 2014). Public Sector Motivation (PSM) has been generally defined by Paarlberg and Lavigna (2010) as:

the beliefs, values, and attitudes that go beyond self-interest and organisational interest to energise employees to do good for others and to contribute to the well-being of organisations and society. (p. 710)

Scholars such as Moynihan and Pandey (2010) have linked general motivational levels that were a result of supportive and constructive leadership styles to superior organisational performance.

The individual and team performance of public sector employees, especially those who interact with the recipients of public sector services, is crucial as their level of performance is usually perceived as that of the entire public sector. In this regard, it also becomes crucially important that public sector policies and strategies be established and implemented to maximise public sector employee performance for the purpose of improving public service delivery.

Therefore, a public sector-based study covering three variables that contribute to organisational performance in the public sector; Perceived Leadership Styles, PSM and Individual Job Performance was deemed necessary for the purpose of improving the performance of individuals, teams and, consequently, the public sector output to society. 


\section{Background to the study}

In 2013, five departments in the province were placed under administration in terms of Section 100 (1) (b) of The Constitution of the Republic of South Africa. This intervention was the result of poor performance in the financial administration and management functions within these departments.

The Section 100 (1) (b) national government intervention led to the conclusion that there were performance issues in the Limpopo province, specifically in the departments that were directly affected by administrative issues. The main problem lay in the diagnosis of performance problems and the solutions that were recommended based on the findings of the diagnostic investigations.

Neglecting the individual level of performance improvement, the diagnosis and both short-term recovery plans and longterm turn-around strategies prioritised the group processes and organisational levels of performance improvement.

The diagnosis process flows from the organisational to the individual performance improvement context (Ulrich, Brockbank, Johnson \& Younger, 2009). It was found necessary, as suggested in Ulrich et al. (2009), to diagnose and improve performance at individual level by focusing on two psychological aspects that drive individuals' performance: their perceptions of their supervisors (Moynihan, Pandey, \& Wright, 2011) and individual motivation levels (Hasnain, Manning \& Pierskalla, 2014).

\section{Trends from the research literature}

In recent literature, performance has been explained as having a relationship with both leadership (Jacobsen \& Andersen, 2014) and motivation (Belle, 2012). Experimental studies were also able to demonstrate the positive effect of Perceived Leadership Styles on employee motivation (Belle, 2013; Frey, Homberg \& Osterloh, 2013; Hasnain et al., 2014; Paarlberg \& Lavigna, 2010; Wright, Moynihan \& Pandey, 2012).

However, public- and private-sector employees do not respond to the same motivation orientations (Frey et al., 2013). Public sector employees are intrinsically motivated, while private-sector employees are extrinsically motivated (Ritz, 2009). Thus, as noted, the dimensions of PSM possess elements that are similar to those of intrinsic motivation.

\section{Research objectives}

\section{Voids and conflicts}

The purpose of this section is to discuss voids and conflicts found in empirical and literature findings as per the three variables of the study.

\section{Leadership and performance}

In addition to the necessity to address the gap of a clear definition of public sector leadership concept, scholars also need to focus on engaging in comparative studies that compare public sector specific leadership dimensions in different countries that have different cultures and values (Tummers \& Knies, 2014). This is important as the value of organisational support and Perceived Leadership Styles may differ from one country to another.

In a study of the effects of leadership styles and performance, Obiwuru, Okwu, Akpa and Nwankwere (2011) found a significant positive relationship between transactional leadership style and performance. The transactional leadership style was first defined in Burns (1978) as a style of leadership where the leader uses tangible rewards that are valued by followers to motivate them to achieve goals desired by the leader and subsequently by the organisation.

The transformational leadership style had a positive impact on performance, its effect was insignificant. The transformational leadership style is heavily based on trust between leaders and followers, which instils confidence that either party in the relationship knows and will do what is necessary to achieve success as defined by both parties (Schaubroek, Lam \& Peng, 2011). Arham (2014) found contradictory results to those of Obiwuru et al. (2011), showing that transformational leadership style resulted in a more significant impact on performance than the transactional leadership style.

However, Bro et al. (2014) adopt an alternative stance to either of the authors just mentioned in that transactional and transformational leadership styles complement rather than oppose each other. When implemented simultaneously, the two leadership styles are capable of achieving higher performance than when one style is used and the other ignored.

\section{Motivation and performance}

In terms of PSM and context, Bozeman and Su (2014) share similar sentiments to those of Tummers and Knies (2014). Bozeman suggests environmental aspects such as individual attitudes and organisational socialisation should be considered when studying PSM. Furthermore, there is a need for experimental studies to reach heights that empirical studies in the field could not (Belle, 2012; Bozeman \& Su, 2014).

Belle (2012) undertook an experimental study that measured the relationship between PSM and Individual Job Performance. The findings of Belle (2012) were that PSM which positively affected the Individual Job Performance of subordinates is manifested in their persistence, output, vigilance and productivity. Belle (2012) also reported that public sector employees are also likely to perform better at their job if their purpose is awakened by direct contact with the people that they serve.

However, contrary to the latter findings of Belle (2012), in their study of police, municipality, school, hospital and 
prison employees, Van Loon, Vandenabeele and Leisink (2015) established that higher PSM amongst employees whose jobs impacted directly on the society resulted in higher job burnout and lower and lower job satisfaction, especially in cases where they could not do much to impact or improve the situations of those that they serve.

\section{Research problem and objectives}

In light of the above voids and conflicts in the literature, the research problem and objectives are discussed below.

\section{Research problem}

It was believed that the general diagnosis of performance problems in the Limpopo province overlooked the individual level of performance improvement. It was therefore necessary to conduct a further diagnosis that focused specifically on the people factor of performance improvement in order to avoid future performance relapses.

Perceptions and motivation of employees are created by the leadership behaviours of their supervisors (Moynihan et al., 2011). Hence, it was proposed that at the individual level of performance, a diagnosis should be conducted by means of analysing the leadership styles of supervisors as perceived by their subordinates and, most importantly, the mediatory role played by the subordinate's levels of PSM in the relationship between Perceived Leadership Styles and Individual Job Performance in the public sector.

\section{Objectives of the study}

The objectives of the study were twofold. Each is briefly discussed below.

\section{Theoretical objectives}

The first objective was to find theoretical grounds to justify the relationship between the three broad variables of the study: leadership (independent variable), performance (dependent variable), and motivation (confounding variable) of the study. The aim was to test and have in place a theoretical model that diagnosed public sector performance issues at individual level.

\section{Practical objectives}

The primary objective was to bring about practical solutions to improve performance in the public sector by focusing on improving performance at the individual level of the performance improvement context. The purpose of the study was to be achieved when the study was able to provide people professionals in the field of performance management with a practical tool, in a form of a model and a set of questionnaires, which could be used to detect public sector performance issues at the individual level of the performance improvement context.

\section{The potential value-add of the study}

The potential value-add of the study was twofold. Each is discussed below.

\section{Theoretical contribution}

As mentioned by Hartog, Boselie and Paauwe (2004), the significance of Individual Job Performance for organisational success is in most cases assumed, rather than tested. Given that the majority of studies in the field of leadership, motivation and performance were conducted in American and European environments, the current study proposed to investigate the associations and relationships between the three variables of the current study using locally collected data that are influenced by the South African public sector environment.

The current study proposed a research agenda that was more specific regarding the factors that affect Individual Job Performance. The confirmed relationships between variables could then be used to solve practical performance issues in the South African public sector, especially at the individual level of performance.

\section{Practical contribution}

One of the most prominent challenges of performance improvement at individual level has been to establish how leaders and managers can manipulate employee motivation in order to foster greater organisational performance (Paarlberg \& Lavigna, 2010). The current study therefore proposed a value-add in terms of practical solutions that would provide people management professionals and linemanagers responsible for performance management with a framework that could be used to detect or diagnose Individual Job Performance issues at the individual level of performance.

In the sections below, the following three sections will be discussed; research design, results, and discussion. Firstly, the research design section will discuss the research approach, method, participants, procedure, measuring instruments, and statistical analysis of the study. Secondly, the results section will cover the descriptive statistics of the scales used in the study and inferential statistics relating to the hypotheses of the study. Thirdly, the discussion section will provide an overview of the study's main objectives and contributions, summary of literature and empirical findings, conclusions and recommendations, and limitations and of the study and suggestions for future research.

\section{Synthesis and critical evaluation of literature Leadership}

In recent literature, leadership has been defined as a skill used by trusted leaders (Schaubroek et al., 2011), to influence followers within a specific context to achieve predetermined organisational goals by using transactional and transformational styles that depend on role expectations of leaders, followers and peers (Arham, 2014).

Leadership that is good, effective and efficient can have a positive impact on and improve organisational performance (Arham, 2014). Therefore, studying various leaders clears the 
path that leads to the understanding of the success of organisations, be these in the public or private sector. In a study of teacher performance in Danish schools, Jacobsen and Andersen (2014) reported a weak correlation between intended and perceived transformational and transactional leadership styles. However, the perceived transactional and transformational leadership styles were found to be related to performance.

Previous empirical and theoretical research has demonstrated that transactional and transformational leadership styles have an impact on employee motivation (Belle 2013; Hasnain et al., 2014). Motivation is accordingly discussed below.

\section{Motivation}

The quest to understand human motivation was initiated thousands of years ago by Greek philosophers who argued that the concept of motivation (Kanfer, 1990), which cannot be observed directly, was a driving force behind all human behaviours (Steers, Mowday \& Shapiro, 2004).

Motivation levels of employees have been said to be the bridge through which leaders can influence the performance of individuals and subsequently of the organisation as a whole (Aslayed, Motaghi \& Osman, 2012). Several studies have also explored the relationship and identified a link between the motivation levels of employees and their performance (Hasnain et al., 2014; Moynihan \& Pandey, 2010).

However, a study that compared PSM research in Europe, the United States, and non-Western countries showed that theoretical and methodological approaches that are used in Western countries are at times not suited for non-Western contexts (Van der Wal, 2014).

\section{The mediating role of Public Sector Motivation between Perceived Leadership Styles and Individual Job Performance}

A number of previous empirical studies have demonstrated the relationship between PSM and both Perceived Leadership Styles (Belle, 2013; Frey et al., 2013; Hasnain et al., 2014; Houston, 2009; Paarlberg \& Lavigna, 2010; Wright et al., 2012), as well as Individual Job Performance (Belle, 2012; Van Loon et al., 2015) in the public sector. However, there is not enough literature, to the researcher's knowledge, that investigated the PSM as a confounding variable in the relationship between the variables of Perceived Leadership Styles and Individual Job Performance.

Although previous studies have explored the relationship between PSM and the variables of Perceived Leadership Styles and Individual Job Performance, separately, Belle (2013) reported that PSM influenced the relationship between Perceived Leadership Styles and Individual Job Performance in the public sector.

\section{Stating hypotheses}

\section{Hypothesis 1}

Belle (2013), Frey et al. (2013), Hasnain et al. (2014), Paarlberg and Lavigna (2010), and Wright et al. (2012) have demonstrated, through experimental research, the positive effect of Perceived Leadership Styles on employee motivation. Thus the first hypothesis proposed was as follows:

- Null Hypothesis 1: There is no positive linear association between Perceived Leadership Styles and Public Sector Motivation.

\section{Hypothesis 2}

The second hypothesis was inspired by Belle (2012) who is convinced, based on experimental research findings, that the relationship between Public Service Motivation and employee performance is directly proportional. Therefore, the second hypothesis is summarised below:

- Null Hypothesis 2: There is no positive linear association between Public Sector Motivation and Individual Job Performance.

\section{Hypothesis 3}

In empirical studies conducted mainly in Western countries, Bro et al. (2014) and Jacobsen and Andersen (2014) found a relationship between leadership and public sector employee performance. Accordingly, this motivated the third hypothesis provided below:

- Null Hypothesis 3: There is no positive linear association between Perceived Leadership Styles and Individual Job Performance.

\section{Hypothesis 4}

The fourth hypothesis was proposed as a result of the empirical findings by Obiwuru et al. (2011) who are of the belief that transactional leadership behaviour leads to better performance in the public sector. The hypothesis is stated as follows:

- Null Hypothesis 4: Subordinates who perceive their supervisor's leadership style as dominantly transactional, have higher Individual Job Performance ratings compared to subordinates who perceive their supervisor's leadership styles as dominantly transformational.

\section{Hypothesis 5}

Based on the empirical findings of Arham (2014), who argues that transformational leadership behaviour is a reliable predictor of public sector performance, the fifth hypothesis reads as follows:

- Null Hypothesis 5: Subordinates who perceive their supervisors' leadership style as dominantly transformational show higher Individual Job Performance ratings compared to subordinates who perceive their supervisor's leadership style as dominantly transactional.

The research design is discussed below.

\section{Research design Research approach}

The study took a positivist approach to be the philosophy of the study. The positivists approach is known to be objective 
in nature. With the objective nature of its premise, the positivist approach is aligned to quantitative methods (Collis \& Hussey, 2014), which made it more suitable for the current study.

The premise of the positivist approach made it suitable for the study given that the ultimate methodological objective of the study was to use objectives-aligned statistical methods to test existing theory and hypotheses on the catalytic role of Public Service Motivation in the relationship between Perceived Leadership Styles and Individual Job Performance in the public sector.

\section{Research method}

With the assumption made in the research approach section above, quantitative methods were selected to also allow for the generalisation of findings to the population from which the sample under study was sourced, that is, the generalisation of findings from the sample to the population of the five Limpopo province departments which were placed under administration.

In addition to their explainable accurate and precise prediction of cause and effect between dependent and independent variables under study, quantitative methods are widely primarily hailed for their reliability and validity in measurement. Numerical data associated with the quantitative method can be obtained quickly, thus saving time and resources (Choy, 2014). Numerical data associated with the current study were obtained quickly by sending out short questionnaires that participants could complete in little time.

The premise of the positivist approach made it suitable for the study as this approach offered the opportunity to use statistical methods such as Spearman's correlation, partial correlation, and linear regression, to test existing theory and hypotheses on the mediatory role of PSM in the relationship between Perceived Leadership Styles and Individual Job Performance in the public sector.

\section{Research participants}

The population for the research was located in one of the 13 departments of the Limpopo Provincial Government of South Africa. The target organisation, as mentioned, was one of the five Limpopo province departments which were placed under administration in terms of Section 100 (1) (b) by the Cabinet of South Africa, making it a desirable location for the study.

Random sampling was adopted as the sampling design for the study. With the researcher using this design, all the members of the population had an equal opportunity of participating in the study (Collis \& Hussey, 2014). With a sampling frame of 198 employees undertaking production and craft jobs, the targeted minimum sample size, as suggested by Collis and Hussey (2014), was 132 participants.
The total sample size for the study was 65 . The profile of the sample in terms of age, gender and years working in the public service is illustrated in frequency tables briefly discussed below. Firstly, the sample was classified in terms of the age of participants.

In Table 1, the largest number of participants, at $44.60 \%$, were between the ages of 20 and 30. Forty per cent of participants were between the ages of 31 and 40, while $9.20 \%$ were between the ages of 41 and 50. Lastly, only $6.20 \%$ of the participants were of age 51 and above.

Secondly, the gender of the participants was also important for the study, thus being recorded in Table 2.

Table 2 shows the frequencies of participants' gender. The majority of participants were females at 50.80\%, while the male gender represented $49.20 \%$ of the participants.

Thirdly, the participants were profiled in terms of their years of employment in the public sector.

Table 3 shows the profile of the participants in terms of their number of years in public sector employment. $73.80 \%$ of participants had worked for a period of 1-10 years in the public sector, while $21.50 \%$ had done so for $11-20$ years. Only $3.10 \%$ of the participants had worked for this sector for 21-31 years, while a mere $1.50 \%$ had worked for 31 years and longer in it.

\section{Measuring instruments}

In addition to the collection of biographical data, two selfreporting instruments were used to collect data on Perceived Leadership Styles and Public Service Motivation. Each of these is briefly discussed below.

\begin{tabular}{lcccc}
\multicolumn{5}{l}{ TABLE 1: Frequencies of participants' age. } \\
\hline Valid & Frequency & Per cent & Valid per cent & Cumulative per cent \\
\hline $20-30$ & 29 & 44.60 & 44.60 & 44.60 \\
$31-40$ & 26 & 40.00 & 40.00 & 84.60 \\
$41-50$ & 6 & 9.20 & 9.20 & 93.80 \\
51 and above & 4 & 6.20 & 6.20 & 100.00 \\
\hline Total & 65 & $\mathbf{1 0 0 . 0 0}$ & $\mathbf{1 0 0 . 0 0}$ & - \\
\hline
\end{tabular}

TABLE 2: Frequencies of participants' gender.

\begin{tabular}{lcccc}
\hline Valid & Frequency & Per cent & Valid per cent & Cumulative per cent \\
\hline Male & 32 & 49.20 & 49.20 & 49.20 \\
Female & 33 & 50.80 & 50.80 & 100.00 \\
\hline Total & $\mathbf{6 5}$ & $\mathbf{1 0 0 . 0 0}$ & $\mathbf{1 0 0 . 0 0}$ & - \\
\hline
\end{tabular}

TABLE 3: Frequencies of participants' years of public service.

\begin{tabular}{lcccc}
\hline Valid & Frequency & Per cent & Valid per cent & Cumulative per cent \\
\hline $1-10$ & 48 & 73.80 & 73.80 & 73.80 \\
$11-20$ & 14 & 21.50 & 21.50 & 95.40 \\
$21-30$ & 2 & 3.10 & 3.10 & 98.50 \\
31 and above & 1 & 1.50 & 1.50 & 100.00 \\
\hline Total & 65 & 100.00 & 100.00 & - \\
\hline
\end{tabular}




\section{Leadership}

To measure the Perceived Leadership Styles, the Multi-factor Leadership Questionnaire (MLQ) Form (5x-Short) was used. The MLQ (5x-Short), consisting of 45 items, was originally developed by Bass and Avollio (1995). With Cronbach's alpha values ranging between 0.89 and 0.95 , the questionnaire was also employed in recent studies (Belle, 2013; Park \& Rainey, 2007). The questionnaire was rated according to a 5-point Likert-scale ranging from 0 (not at all) to 4 (frequently if not always).

\section{Motivation}

For the purpose of the current study, the original PSM scale, which has been employed in similar recent studies (Belle, 2013; Moynihan \& Pandey, 2010) with an overall Cronbach's alpha of 0.90, was used. The Cronbach's alpha for the four independent dimensions ranged between 0.69 and 0.74 (Perry, 1996). The 5-point Likert-scale ranged from 0 (not at all) to 4 (frequently if not always).

\section{Research procedure}

The study was conducted in one organisation, the Limpopo Provincial Treasury. Two instruments were combined into one questionnaire of two pages in length. Data were collected in two rounds. In the first round, the questionnaire was distributed to the entire sampling frame of 292 using the internal e-mailing system. For the second round, the hard copies of the questionnaire were printed and distributed to participants during arranged one-on-one meetings to improve the response rate. The completed copies of the questionnaires were collected and safely stored.

\section{Statistical analysis}

The Statistical Package for the Social Sciences (IBM SPSS Statistics 22) in consultation with the STATKON office at the University of Johannesburg, was employed to analyse the data from both the first and second rounds of data collection. The software was used so as to maximise accuracy and reliability of findings. It was utilised to generate the following groups of statistics.

\section{Inferential statistics}

\section{Factor analysis}

Factor analysis was made use of as a technique to reduce the number of items in the questionnaire, thus reducing the data to be collected for the study. Factor analysis summarises a large number of variables into smaller factors that are manageable (Pallant, 2013). Factor analysis was run to generate factor loadings that determined the correlations between the factors of each of the three variables, which were measured on rating scales.

\section{Scale validity and reliability}

Two of the variables of the study, Perceived Leadership Styles and PSM, were explanatory. Explanatory variables are abstract and contain hypothetical constructs that are not directly observable, thus providing ground for the necessity of validity and reliability tests (Collis \& Hussey, 2014).

Validity testing was conducted to determine whether the instruments used in the study measured what they were intended to (Collis \& Hussey, 2014). The said instruments were validated by previous extensive research conducted by Bass and Avolio (1995) and Perry (1996) and, as noted, measured Perceived Leadership Styles and PSM, respectively.

For the current study, Cronbach's alpha coefficients were generated to determine the internal reliability and inter-item correlations of each of the two multiple-item scales used in the study, the MLQ (5x-short) and PSM scale.

\section{Descriptive statistics}

Descriptive statistics allow for the measuring of central tendency, dispersion of data, and examination of frequency distributions (Collis \& Hussey, 2014). For the purpose of the current study, descriptive statistics were generated to allow for the summarising of data into frequency tables of the biographical data collected.

\section{Spearman's correlation}

To measure the linear association between variables, the Spearman's correlation was utilised. This required the availability of non-parametric data for two variables collected using an interval, ratio or ordinal scale (Collis \& Hussey, 2014). For the purpose of the current study, this technique was applied to measure the association between the independent variable of Perceived Leadership Styles and the dependent variable of Individual Job Performance.

\section{Linear regression}

Provided that there is a linear relationship between two variables under study, linear regression is employed to measure the extent to which the independent variable can predict the outcome of the dependent variable (Collis \& Hussey, 2014). For the purpose of the current study, linear regression was generated to measure the ability of Perceived Leadership Styles and to predict the outcome of Individual Job Performance.

\section{Partial correlation}

The generation of partial correlation is necessary if there is a confounding variable that is suspected to be influencing the two variables that are of main interest. The variable can be statistically removed in order to determine the relationship between the two variables of interest with accuracy (Pallant, 2013). In the current study, PSM was identified and used as a confounding variable.

This variable was suspected to influence the relationship between Perceived Leadership Styles and Individual Job Performance. Thus, partial correlation was generated to 
control the impact of PSM on the relationship between Perceived Leadership Styles and Individual Job Performance.

\section{Results \\ Descriptive and reliability statistics of scales}

The results of the reliability tests for the two instruments used in the current study are discussed below.

\section{Public Sector Motivation Scale}

The reliability statistics of the Public Service Motivation Scale are shown in Table 4.

In the current study, as evident in Table 4, the overall Cronbach's alpha coefficient of the PSM scale with a total of 14 items and 4 dimensions is 0.46 . The Cronbach's alpha coefficient failed to meet the minimum value of 0.70 for internal consistency as recommended by Pallant (2013).

Indeed, only one dimension of the scale met the conditions that are required for good internal consistency. The selfsacrifice dimension had a Cronbach's alpha coefficient of 0.71, while the other remaining three dimensions had coefficients that ranged from -0.23 to 0.63 . The negative Cronbach's alpha value indicates a weak negative inter-item correlation between the items of the attraction to public policy variable. To address the weak internal consistency, the reliability analysis was rerun using the reverse-coding method.

However, even with the reverse-coding of the variable, the Cronbach's alpha value stayed the same at -0.23 . For this reason, the attraction to public policy construct and its two items were discarded. The three constructs of self-sacrifice, compassion and commitment to public interest were retained.

\section{Multi-factor Leadership Questionnaire}

The reliability statistics of the MLQ are depicted in Table 5.

TABLE 4: Reliability statistics of the Public Sector Motivation scale.

\begin{tabular}{lcc}
\hline Scale & Number of items & Cronbach's alpha \\
\hline Self-sacrifice & 3 & 0.71 \\
Compassion & 3 & 0.55 \\
Commitment to public interest & 3 & 0.63 \\
Attraction to public policy & 2 & -0.23 \\
\hline Total & $\mathbf{1 4}$ & $\mathbf{0 . 4 6}$ \\
\hline
\end{tabular}

TABLE 5: Reliability statistics of the Multi-factor Leadership Questionnaire.

\begin{tabular}{lcc}
\hline Scale & Number of items & Cronbach's alpha \\
\hline Idealised influence & 4 & 0.81 \\
Individualised consideration & 4 & 0.87 \\
Inspirational motivation & 2 & 0.61 \\
Intellectual stimulation & 4 & 0.67 \\
Laissez-Faire leadership & 2 & 0.83 \\
Management by exception (active) & 2 & 0.69 \\
Management by exception (passive) & 4 & 0.66 \\
\hline Total & $\mathbf{2 2}$ & $\mathbf{0 . 7 3}$
\end{tabular}

Table 5 illustrates the reliability statistics of the MLQ that consisted of a total of 22 items and 7 dimensions. The overall Cronbach's alpha coefficient was 0.73 which, according to Collis and Hussey (2014), means that the scale can produce reliable findings that are accurate and precise.

Three individual dimensions had a coefficient value of more than 0.8, exceeding the Cronbach's alpha coefficient recommended by Collis and Hussey (2014). The remaining individual four dimensions recorded coefficient values that ranged between 0.61 and 0.69 , which is slightly lower than the minimum recommended Cronbach's alpha coefficient of 0.70 as recommended by Pallant (2013).

\section{Inferential statistics}

The purpose of this section is to test hypotheses using the correlation analysis method. The overall results of this analysis are found in Table 6.

The testing of hypotheses of the study is based on the correlation analysis results in Table 6. The subsections below highlight these results.

\section{Hypothesis 1}

Hypothesis 1 was tested using the correlation analysis of the association between Perceived Leadership Styles and PSM. The results are depicted in Table 7.

The results in Table 7 are based on Perceived Leadership Styles as an independent variable and PSM as a dependent variable. For a sample size of 65 participants, the results showed a correlation coefficient of 0.02 and a $p$-value of 0.89 .

The findings of $r=0.02, n=65, p<0.01$ indicate that there is a low positive correlation between Perceived Leadership Styles and PSM. However, the $p$-value of 0.89 indicates that the results are insignificant at the $1 \%$ level. Therefore, the researcher fails to reject the null hypothesis at $p \leq 0.01$ because of the results being insignificant at $1 \%$ significance level.

TABLE 6: The overall correlation analysis of the three variables in the study.

\begin{tabular}{llccc}
\hline Spearman's rho & Coefficient & Performance & Leadership & Motivation \\
\hline Performance & Correlation coefficient & 1.00 & -0.040 & 0.14 \\
& Sig. (2-tailed) & - & 0.759 & 0.25 \\
& $N$ & 65.00 & 65.000 & 65.00 \\
Leadership & Correlation coefficient & -0.04 & 1.000 & 0.02 \\
& Sig. (2-tailed) & 0.76 & - & 0.89 \\
& $N$ & 65.00 & 65.000 & 65.00 \\
\multirow{4}{*}{ Motivation } & Correlation coefficient & 0.14 & 0.020 & 1.00 \\
& Sig. (2-tailed) & 0.25 & 0.890 & - \\
& $N$ & 65.00 & 65.000 & 65.00 \\
\hline
\end{tabular}

TABLE 7: Correlation analysis between Perceived Leadership Styles and Public Sector Motivation.

\begin{tabular}{llc}
\hline Spearman's rho & Coefficient & Motivation \\
\hline Leadership & Correlation coefficient & 0.02 \\
& Sig. (2-tailed) & 0.89 \\
& $N$ & 65.00 \\
\hline
\end{tabular}




\section{Hypothesis 2}

Hypothesis 2 was tested using the correlation analysis of the association between PSM and Individual Job Performance. The results of the analysis are reported in Table 8.

The results in Table 8 are based on PSM as an independent variable and individual performance as a dependent one. The results indicate a correlation coefficient of 0.14 and a $p$-value of 0.25 .

The $r=0.14, n=65, p<0.01$, indicate that there is a low positive correlation between Perceived Leadership Styles and PSM. However, the $p$-value of 0.25 means that one must fail to reject the null hypothesis at $p \leq 0.01$ as the results are insignificant at $1 \%$ significance level.

\section{Hypothesis 3}

Correlation analysis was used to test hypothesis 3 on the association between Perceived Leadership Styles and Individual Job Performance. The results are presented in Table 9 .

The results depicted in Table 9 are based on leadership as an independent variable and individual performance as a dependent one for a sample size of 65 participants. The results yield a correlation coefficient of -0.04 and a $p$-value of 0.76 .

The $r=-0.04, n=65, p<0.01$ means that there is a low negative correlation between Perceived Leadership Styles and Individual Job Performance. However, the $p$-value of 0.76 indicates that the results are insignificant at the $1 \%$ level. For this reason, the researcher fails to reject the null hypothesis at $p \leq 0.01$.

\section{Hypothesis 4}

Hypothesis 4 was tested using the correlation analysis of the association between transactional leadership and Individual Job Performance. Such leadership, as mentioned, is divided into three dimensions: management by passive exception (MEP), management by active exception (MEA), and contingent reward (Moynihan et al., 2011). For the purposes of the current study, only the dimensions MEP and MEA were combined to make up transactional leadership as shown in Table 10.

TABLE 8: Correlation analysis between Public Sector Motivation and Individual Job Performance.

\begin{tabular}{llc}
\hline Spearman's rho & Coefficient & Performance \\
\hline Motivation & Correlation coefficient & 0.14 \\
& Sig. (2-tailed) & 0.25 \\
& $N$ & 65.00 \\
\hline
\end{tabular}

TABLE 9: Correlation analysis between Perceived Leadership Styles and Individual Job Performance.

\begin{tabular}{llc}
\hline Spearman's rho & Coefficient & Performance \\
\hline Leadership & Correlation coefficient & -0.04 \\
& Sig. (2-tailed) & 0.76 \\
& $N$ & 65.00 \\
\hline
\end{tabular}

The results of the analysis in Table 10 are such that transactional leadership is the independent variable and Individual Job Performance the dependent one. The correlation coefficient of transactional leadership is a combination of the correlation coefficients of $\operatorname{MEP}(r=-0.03$, $p=0.80)$ and MEA $(r=-0.13, p=0.31)$. Thus, for a sample size of 65 participants, transactional leadership shows a correlation coefficient value of -0.22 and a $p$-value of 0.56 .

The results of $r=-0.22, n=65, p<0.01$ indicate that there is a low negative correlation between the transactional leadership style and Individual Job Performance. The $p$-value of 0.56 indicates that the results are insignificant at the $1 \%$ level. Thus, the researcher fails to reject the null hypothesis at $p \leq 0.01$.

\section{Hypothesis 5}

Correlation analysis was again used to test hypothesis 5 . The focus was to analyse the association between transformational leadership and Individual Job Performance. It has been pointed out that transformational leadership comprises four dimensions: inspirational motivation (IM), individualised consideration (IC), idealised influence (II), and intellectual stimulation (IS). The results of the analysis are provided in Table 11.

TABLE 10: Correlation analysis between transactional leadership and Individual Job Performance.

\begin{tabular}{llc}
\hline Spearman's rho & Coefficient & Performance \\
\hline MEP & Correlation coefficient & -0.03 \\
& Sig. (2-tailed) & 0.80 \\
& $N$ & 65.00 \\
MEA & Correlation coefficient & -0.13 \\
& Sig. (2-tailed) & 0.31 \\
Transactional Leadership & $N$ & 65.00 \\
& Correlation coefficient & -0.22 \\
& Sig. (2-tailed) & 0.56 \\
& $N$ & 65.00 \\
\hline
\end{tabular}

MEP, management by passive exception; MEA, management by active exception.

TABLE 11: Correlation analysis between transformational leadership and Individual Job Performance.

\begin{tabular}{llc}
\hline Spearman's rho & Coefficient & Performance \\
\hline II & Correlation coefficient & -0.10 \\
& Sig. (2-tailed) & 0.44 \\
& $N$ & 65.00 \\
IS & Correlation coefficient & -0.14 \\
& Sig. (2-tailed) & 0.28 \\
& $N$ & 65.00 \\
IM & Correlation coefficient & -0.04 \\
& Sig. (2-tailed) & 0.74 \\
& $N$ & 65.00 \\
IC & Correlation coefficient & -0.03 \\
& Sig. (2-tailed) & 0.81 \\
& $N$ & 65.00 \\
Transformational Leadership & Correlation coefficient & -0.08 \\
& Sig. (2-tailed) & 0.57 \\
& $N$ & 65.00 \\
\hline
\end{tabular}

II, idealised influence; IS, intellectual stimulation; IM, inspirational motivation; IC, individualised consideration. 
The results in Table 11 are based on transformational leadership as an independent variable and Individual Job Performance as a dependent one. The transformational leadership correlation coefficient is a total combination of the correlation coefficients of II $(r=-0.10, p=0.44)$, IS $(r=-0.14$, $p=0.28), \operatorname{IM}(r=-0.04, p=0.74)$, IC $(r=-0.03, p=0.81)$. Thus, the results of transformational leadership are as follows: $r=-0.08, p=0.57, n=65$.

The $r=-0.08, n=65, p<0.01$ indicates a perceived low negative correlation between transformational leadership and Individual Job Performance. However, the $p$-value of 0.57 indicates that the results are insignificant at the $1 \%$ level. The $p$-value leads to the rejection of the null hypothesis at $p \leq 0.01$.

\section{Discussion}

\section{The main objectives of the study}

The objectives of the study were grouped into three categories: theoretical, methodological and practical.

Firstly, given that the majority of theory in the literature related to the problem statement of the current study stemmed mostly from Western countries, the main theoretical objective was to produce findings that would allow for the generation of theory which explained the relationship of the variables of the current study in a South African context.

Lastly, the practical objective was to produce findings that could be used on a daily basis by managers who sought to enhance the performance of the organisation through improving the Individual Job Performance of their subordinates.

\section{The main contributions of the study \\ Theory}

It will be recalled that the theoretical objective of the study was to investigate the theoretical relationship between Perceived Leadership Styles, PSM, and Individual Job Performance. The study was able to explore the relationship between Perceived Leadership Styles and PSM, and Individual Job Performance in the public sector. However, there was not enough previous literature that explicitly investigated PSM as a confounding variable in the relationship between Perceived Leadership Styles and Individual Job Performance in the public sector.

Therefore, the current study added value to theory in that its investigation focused on an overlooked area in the study of performance in the public sector, that is, the role of PSM as a confounding variable in the relationship between Perceived Leadership Styles and Individual Job Performance in the public sector.

\section{Practice}

The practical objective of the study was to contribute to public sector performance improvement by producing a framework that could be used to detect performance problems at the individual level.

The current study was able to meet the objective as it managed to produce a single questionnaire that could be used to measure how the Perceived Leadership Styles of supervisors may affect the Individual Job Performance of subordinates while taking into account the subordinate's PSM levels. The current study has added a practical value in that it was able to produce a tool that should be able to provide information to assist people professionals in the field of performance in the public sector to make better performance improvement strategy decisions.

\section{Summary of results}

The study consisted of five hypotheses which were informed by previous literature and empirical findings. The hypotheses and findings were as follows:

- Null Hypothesis 1: There is no positive linear association between Perceived Leadership Styles and Public Sector Motivation.

- A low positive correlation was found between Perceived Leadership Styles and Public Service Motivation.

- Null Hypothesis 2: There is no positive linear association between Public Sector Motivation and Individual Job Performance.

- The results showed that there was a low positive correlation between PSM and Individual Job Performance.

- Null Hypothesis 3: There is a no positive linear association between Perceived Leadership Styles and Individual Job Performance.

- It was established that there was a low negative correlation between Perceived Leadership Styles and Individual Job Performance.

- Null Hypothesis 4: Subordinates who perceive their supervisor's leadership style as dominantly transactional, have higher Individual Job Performance ratings compared to subordinates who perceive their supervisor's leadership styles as dominantly transformational.

- The results demonstrated a low negative correlation between transactional leadership style and Individual Job Performance.

- Null Hypothesis 5: Subordinates who perceive their supervisors' leadership style as dominantly transformational show higher Individual Job Performance ratings compared subordinates who perceive their supervisor's leadership style as dominantly transactional.

- A low negative correlation was found between transformational leadership style and Individual Job Performance.

However, because of $p$ values that were greater than 0.01 , the five hypotheses were rejected at $p \leq 0.01$, and all the findings were insignificant at the $1 \%$ significance level. 


\section{Conclusion and recommendations}

\section{Perceived Leadership Styles versus Individual Job Performance}

Both the literature review and empirical findings indicate that a correlational relationship exists between Perceived Leadership Styles and Individual Job Performance. However, the findings from the literature review show a positive correlation between the two variables while the empirical findings of the current study yield a negative correlation. Based on the findings from the literature review, it is concluded that employees who rate the leadership styles of their supervisors positively tend to exhibit high Individual Job Performance.

Therefore, it is recommended that to avoid future performance difficulties, the Limpopo Provincial Government should focus on the development of leadership competencies of managers and supervisors within their departments. Through customised Management Development Programmes, managers and supervisors must be made aware of the impact of their leadership styles on the performance of their subordinates.

\section{Transactional and transformational leadership styles versus Individual Job Performance}

Similar to the correlational findings of the relationship between Perceived Leadership Styles and Individual Job Performance, the breaking down of the Perceived Leadership Styles variable into transactional and transformational leadership styles in the current study pointed to conflicting findings from the literature review and the empirical research.

By means of establishing positive correlation coefficients, the reviewed literature indicated that the transformational leadership style had more impact, compared to the transactional leadership style, on Individual Job Performance. However, by means of determining a negative correlation coefficient, the empirical findings of the current study revealed that a transactional leadership style, as opposed to a transformational leadership style, had more impact on Individual Job Performance.

Based on both the literature and empirical findings, it is concluded that both transactional and transformational leadership styles have a role to play in inspiring greater Individual Job Performance. Thus, it is recommended that the Management Development Programmes which should be implemented to prevent future performance issues in the Limpopo Provincial Government should emphasise the importance of both transactional and transformational leadership styles.

\section{Public Sector Motivation versus Individual Job Performance}

The findings from the literature review indicated that high levels of PSM had a negative impact on Individual Job Performance. Because of undesirable working conditions and lack of resources, public sector employees with high levels of PSM are most likely to experience high stress levels, which then affect the execution of their tasks; thus, they perform poorly in their jobs. However, the empirical findings of the current study produced results that were opposite to those in the reviewed literature, in other words that PSM was positively correlated to Individual Job Performance.

Based on both the literature review and the empirical findings, it is concluded that PSM plays an important role in determining Individual Job Performance in the public sector. Therefore, it is recommended that the Limpopo Provincial Government should minimise the demotivation of public service employees by improving working conditions and the availability of resources, to allow public sector employees to be motivated to do their work more effectively.

\section{Perceived Leadership Styles versus Public Sector Motivation}

Both literature review and empirical findings are in line regarding the relationship between Perceived Leadership Styles and PSM. Both sets of findings showed a positive correlation between these variables.

Guided by both sets, it is concluded that high levels of PSM are likely to be witnessed in subordinates who perceive the leadership style of their supervisors positively. Therefore, it is recommended that the Limpopo Provincial Government should focus on developing leadership competencies of managers and supervisors within their departments for the purpose of evoking PSM in their subordinates. The existence and importance of PSM should be embedded in the recommended Management Development programme for managers and supervisors.

\section{The mediatory role of Public Sector Motivation in the relationship between Perceived Leadership Styles and Individual Job Performance}

Although previous studies have explored the relationship between PSM and the variables of Perceived Leadership Styles and Individual Job Performance, separately, Belle (2013) reported that PSM influenced the relationship between Perceived Leadership Styles and Individual Job Performance in the public sector. The empirical findings of the current study confirmed the findings in literature by demonstrating that PSM was indeed a confounding variable in the relationship between Perceived Leadership Styles and Individual Job Performance.

Based on both the empirical and literature review findings, it is concluded that PSM plays a mediatory role between Perceived Leadership Styles and Individual Job Performance. Therefore, it is important that the Limpopo Provincial Government makes an effort to employ and retain employees who are readily showing high levels of PSM. It is recommended that the Limpopo Provincial Government uses the Public Service Motivation Scale as an assessment to assist in the selection of new employees and retaining existing ones. 


\section{Limitations of the study}

Both literature review and empirical findings of the study had contextual and applicability limits. The literature review findings, as acknowledged, were based on environmental contexts that were different from the local South African context, therefore making the applicability of such findings in the local context questionable. The majority of the empirical findings were insignificant at $1 \%$ significance level, consequently limiting the applicability of the findings in practice.

\section{Suggestions for future research}

The literature review findings reveal that more research is needed into the impact of PSM as a confounding variable in the relationship between Perceived Leadership Styles and Individual Job Performance, specifically in the public sectors of African countries. From an empirical finding's perspective, future research should ensure that the collected data are gathered from sample sizes that are congruent with the population under study. Larger samples will assist in boosting the significance and generalisability of findings. Future studies should also employ electronic means of collecting data to access larger numbers of participants.

Most importantly, future studies should use data collection instruments that are language-adapted to minimise any ambiguity of items and maximise the common understanding of such items by the targeted samples. The adaptation could also assist in maximising the questionnaire response rate of the studies.

\section{Acknowledgements Competing interests}

The authors declare that they have no financial or personal relationships that may have inappropriately influenced them in writing this article.

\section{Authors' contributions}

The study was conducted by D.M. as part of his Master's thesis at the University of Johannesburg. M.H.R.B. was the supervisor and co-wrote the article.

\section{References}

Arham, A.F. (2014). Leadership and performance: The case of Malaysian SMEs in the service sector. International Journal of Asian Social Science, 4(3), 343-355.

Aslayed, A.K., Motaghi, M.H., \& Osman, I.B. (2012). The use of the Multifactor Leadership Questionnaire and Communication Satisfaction Questionnaire in Palestine: A research note. International Journal of Scientific and Research Publications, 2(11), 1-9.

Bass, B.M., \& Avolio, B.J. (1995). MLQ Multi-leadership questionnaire. Redwood City, CA: Mind Garden.

Belle, N. (2012). Experimental evidence on the relationship between Public Service Motivation and job performance. Public Administration Review, 73(1), 143-153. https://doi.org/10.1111/j.1540-6210.2012.02621.x

Belle, N. (2013). Leading to make a difference: A field experiment on the performance effects of transformational leadership, perceived social impact, and Public Service Motivation. Journal of Public Administration Research and Theory Advance Access, 1(1), 1-28.
Bozeman, B., \& Su, X. (2014). Public Service Motivation concepts and theory: A critique. Public Administration Review, 1(1), 1-11.

Bro, L.L., Andersen, L.B., Bollingtoft, A., Eriksen, T., Holten, A., Jacobsen, C.B., et al. (2014). Leadership training, leadership strategies and organisational performance: Designing an experiment to test the causal effect of leadership on performance. Ottawa: Paper presented on the IRPSM conference.

Burns, J.M. (1978). Leadership. New York: Harper \& Row.

Choy, L.T. (2014). The strengths and weaknesses of research methodology: Comparison and complimentary between qualitative and quantitative approaches. Journal of Humanities and Social Science, 19(04), 99-104.

Collis, J. \& Hussey, R. (2014). Business research: A practical guide for undergraduate \& postgraduate students. New York: Palgrave McMillan. https://doi.org/10.1007/ 978-1-137-03748-0

Frey, B.S., Homberg, F., \& Osterloh, M. (2013). Organisational control systems and payfor-performance in the public service. Organisations Studies, 34(7), 949-972. https://doi.org/10.1177/0170840613483655

Hartog, D.N., Boselie, P., \& Paauwe, J. (2004). Performance management: A model and research agenda. Journal of Economic Literature, 1-21. Retrieved May 20, 2015, research agenda. Journal of Economic Literature, 1-21. Retrieved May 20, 2015, from http://wWW.scribd.com/doc/2530136/Hartog-D-N-Bos

Hasnain, Z., Manning, N., \& Pierskalla, J.H. (2014). The promise of performance pay? Reasons for caution in policy prescriptions in the Core Civil Service. International Bank for Reconstruction and Development, 29, 1-30. https://doi.org/10.1093/ wbro/lku001

Houston, D.J. (2009). Motivating knights or knaves? Moving beyond performancerelated pay for the public sector. Public Administration Review, 69(1), 43-57.

Jacobsen, C.B., \& Andersen, L.B. (2014). Is leadership in the eye of the beholder? A study of intended and perceived leadership strategies and organisational performance. Copenhagen: The Rockwool Foundation Research Unit.

Kanfer, R. (1990). Motivation theory and industrial and organisational psychology. Palp Alto: Consulting Psychologists Press.

Moynihan, D.P., \& Pandey, S.K. (2010). The big question for performance management: Why do managers use performance information? Journal of Public Administration Research and Theory, 20, 849-866. https://doi.org/ 10.1093/jopart/muq004

Moynihan, D.P., Pandey, S.K., \& Wright, B.E. (2011). Setting the table: How transformational leadership fosters performance information use. Journal of Public Administration Research and Theory, 22, 143-164. https://doi.org/10.1093/ jopart/mur024

Obiwuru, T.C., Okwu, A.T., Akpa, V.O., \& Nwankwere, I.A. (2011). Effects of leadership style on organisational performance. Journal of Business and Management Research, 1(7), 100-111.

Paarlberg, L.E., \& Lavigna, B. (2010). Transformational leadership and public service motivation: Driving individual and organisational performance. Public Administration Review, 70(5), 710-716. https://doi.org/10.1111/j.1540-6210.2010.02199.x

Pallant, J. (2013). SPSS Survival Manual: A step by step guide to data analysis using IBM SPSS. Crows Nest: Allen \& Unwin.

Park, S.M. \& Rainey, H.G. (2007). Antecedents, mediators, and consequences of affective, normative, and continuance commitment: Empirical tests of commitment effects in federal agencies. Review of Public Personnel Administration, 27(3), 197-226. https://doi.org/10.1177/0734371X06296866

Perry, J.L. (1996). Measuring public service motivation: An assessment of construct reliability and validity. The Journal of Public Administration Research and Theory, 6(1), 5-22. https://doi.org/10.1093/oxfordjournals.jpart.a024303

Ritz, A. (2009). Public service motivation and organisational performance in Swiss federal government. International Review of Administrative Sciences, 75(1), 53-78. https://doi.org/10.1177/0020852308099506

Schaubroek, J., Lam, S.S.K., \& Peng, A.C. (2011). Cognition-based and affect-based trust as mediators of leader behaviour influences on team performance. Journal of Applied Psychology, 96(4), 863-871. https://doi.org/10.1037/a0022625

Steers, R.M., Mowday, R.T., \& Shapiro, D.L. (2004). Introduction to special topic forum: The future of work motivation theory. Academy of Management Review, 29(3), 379-387. https://doi.org/10.2307/20159049

Tummers, L., \& Knies, E. (2014). The public leadership questionnaire: The development and validation of five dimensions of public leadership behaviours. Conference proceedings of the IRSPM Conference held in Ottowa. Conducted by Panel "New proceedings of the IRSPM Conference held in Ottowa. Conducted by Panel "New Direction
Ottowa.

Ulrich, D., Brockbank, W., Johnson, D., \& Younger (2009). Human Resource Competencies: Rising to meet the business ., \& Yllenge. The RPL white Resource Competencies: March 30, 2016, from http://www.hrnorge.no/wpcontent/uploads/2013/07/ March 30, 2016, from http://www.hrnorge.no/wpcontent/uploads
HumanResourceCompetenciesRisingtomeetthebusinesschallenge.pdf

Van der Wal, Z. (2014). "All quiet on the non-Western front?" A systematic literature review of Public Service Motivation scholarship in non-Western contexts. Asia Pacific Journal of Public Administration, 1(1), 1-19.

Van Loon, N., Vandenabeele, W., \& Leisink, P.L.M. (2015). On the bright and dark side of Public Service Motivation: Investigating the relationship between PSM and employee wellbeing from an institutional perspective. Public Money and Management, 1(1), 1-30.

Wright, B.E., Moynihan, D.P., \& Pandey, S.K. (2012). Pulling the levers: Transformational leadership, public service motivation, and mission valence. Public Administration Review, 72(2), 206-215. https://doi.org/10.1111/j.1540-6210.2011.02496.x 